\title{
How to make job planning work
}

New contracts were recently accepted across the devolved nations of the UK as the basis for all future consultant employment in the National Health Service (NHS). All existing consultants have the choice of transferring to the Terms and Conditions of Service 2003 (Department of Health, 2003) or remaining on their existing contract.

The new contract's basis is that consultants perform ten programmed activities (PAs) a week, typically each of $4 \mathrm{~h}$ duration. The European Working Time Directive (EWTD) requires employees working more than $48 \mathrm{~h}$ a week to opt-out, in writing, of statutory protection. As PAs performed in premium time (19.00-07.00 h) are of $3 \mathrm{~h}$ duration, an EWTD-adherent job plan can comprise more than 12 PAs without requiring the use of the opt-out.

The job plan is an agreement between the employer and employee over what activities will take place, for how long and where, and agreement is made annually. Guidance exists as to how many PAs should be allocated to different types of work and these are defined in the terms and conditions: direct clinical care, supporting professional activities, additional responsibilities, other duties and external duties. The terms and conditions specify that typically consultants should have 2.5 supporting professional activities, and up to 7.5 direct clinical case activities.

\section{Effective job planning}

To job plan successfully, consultants will need to keep a diary of all their activities (NHS Modernisation Agency, 2003). Ideally, this should be compiled over a period long enough to be representative. Thus, where bimonthly clinics occur then 2 months is required; if every week were the same, then 1 week would be sufficient. Where there are irregular obligations, such as College work, interview panels or other duties, it is possible to annualise them, and then break them down into weekly fractions of a programmed activity. For example, 3 days as an examiner for one of the Colleges should be recorded as the number of PAs spent examining, including the travel time, premium work and related administration. Thus, ten PAs, or more, might be involved per year.

Of the 52 weeks in the year, 10 weeks are lost to annual/study leave and public holidays. For the job plan, these ten PAs occur over a 42-week period, equal to 0.24 (10/42) of a PA per week, and similar arithmetic can be applied to all responsibilities. Unfortunately, the failure of employers to adequately recognise the time involved in College activities, for example, is commonplace

(Chaudhray, 2004; Walker, 2004).

In some trusts, directorate-wide agreements on aspects of job planning have been reached. Examples

\begin{tabular}{|c|c|c|}
\hline Activity & Example & Band \\
\hline \multirow{9}{*}{$\begin{array}{l}\text { Direct clinical } \\
\text { care }\end{array}$} & Emergency attendance & C1 \\
\hline & Out-patient or other clinic & $\mathrm{C} 2$ \\
\hline & Ward round & $\mathrm{C3}$ \\
\hline & $\begin{array}{l}\text { Other patient treatment or } \\
\text { relative consultation }\end{array}$ & $\mathrm{C} 4$ \\
\hline & Telephone advice to hospital & C6 \\
\hline & $\begin{array}{l}\text { Multidisciplinary meeting about } \\
\text { direct patient care }\end{array}$ & C7 \\
\hline & $\begin{array}{l}\text { Investigative, diagnostic or } \\
\text { laboratory work }\end{array}$ & C8 \\
\hline & Travelling time between sites & C10 \\
\hline & Patient administration & C11 \\
\hline \multirow{7}{*}{$\begin{array}{l}\text { Supporting } \\
\text { professional } \\
\text { activities }\end{array}$} & Training & S1 \\
\hline & CPD & $\mathrm{S} 2$ \\
\hline & Teaching & S3 \\
\hline & Audit/clinical governance & S4 \\
\hline & Job planning/appraisal & S5 \\
\hline & Research & S6 \\
\hline & Clinical management & S7 \\
\hline \multirow{5}{*}{$\begin{array}{l}\text { Additional } \\
\text { responsibilities }\end{array}$} & Caldicott guardian & A1 \\
\hline & Audit/clinical governance & A2 \\
\hline & Clinical tutor & A3 \\
\hline & $\begin{array}{l}\text { Medical/clinical directors and } \\
\text { lead clinicians }\end{array}$ & A4 \\
\hline & Additional responsibilities & A5 \\
\hline \multirow{5}{*}{$\begin{array}{l}\text { Other duties or } \\
\text { external duties }\end{array}$} & Trade union duties & D1 \\
\hline & AAC external member & D2 \\
\hline & NCAA, GMC, HC & D3 \\
\hline & Work for Colleges & D4 \\
\hline & Other & D5 \\
\hline
\end{tabular}

CPD, continuing professional development; AAC, Appointments Advisory Committee; NCAA, National Clinical Assessment Authority; GMC, General Medical Council; HC, Health Commission.

include agreements that supporting professional activities may be conducted off-site or flexibly (e.g. continuing professional development performed at weekends or in the evening, or that direct clinical care may be cancelled to lecture at local courses). Producing College guidelines can be persuasive; the Senate of Surgery (personal communication) has written to the Director, Human Resources, Department of Health, that all on-call surgeons must be available to return to work immediately (band A), because of the needs of trainees and patients.

When a disagreement is about other duties, consultants could point out that the Director of Human Resources for the NHS Executive stated in his letter (EL (95)93): 'I would like to encourage employers, as part of their obligations as part of the NHS, to release consultants for a range of duties such as advising the $\mathrm{DoH}$, participating in college duties or examining. These are
See p. 387, this issue. 
(8)

special articles examples of work necessary for the broader benefit of the NHS but which involve consultants being away from their employment base'. The Modernisation Agency's Consultant Contract Implementation Team made the same points (NHS Modernisation Agency, 2004a).

\section{Difficulties in reaching mutual understanding}

Some trusts are reluctant to implement the job plan supplied. Management may identify inappropriate work patterns or activities; however PAs in excess of ten may legitimately be necessary for a wider service. Where an impasse is reached and both parties cannot agree on which PAs can and should be removed from the job plan, such as a clinic, emergency cover, etc., a request for mediation can be made. This should be made in writing to the medical director, with an explanation of what the areas of disagreement are and why the proposed job plan is unreasonable. If the medical director had been directly involved in the decision not to implement the proposed job plan then it would be inappropriate for them to mediate. Where practitioners have access to an employment advisor or union representative their advice and support is best sought at an early stage.

Mediation can be valuable; examples include clarification of a mismatch between non-clinical managerial expectations and those of clinical directors; clarity over time commitments expected of the consultant or flexibility in clinical work that had not been previously agreed between the parties.

If agreement cannot be reached at mediation there remains formal appeal (NHS Modernisation Agency, 2004b). The appeals process involves a chairperson nominated by the employer, not previously involved in the dispute, a representative nominated by the consultant and a third member from a list agreed between the Strategic Health Authority and the British Medical Association. This panel will consider written and oral evidence and make a written recommendation to the employing organisation. Where there is significant disagreement within a directorate about job planning the prospect of multiple appeals could be daunting to management.

\section{Conclusion}

Job planning is a time-consuming and intensive experience, but proper preparation and commitment to delivering quality care can produce a better understanding of the time involved for both trusts and consultants. This becomes the foundation for a mutually acceptable solution. Persistence in explaining the necessary commitments can produce results that profit all parties.

\section{Declaration of interest}

M.E.J.W. is a representative on the British Medical Association's Central Consultant's Committee and is secretary of the Central \& North West London Mental Health NHS Trust Local Negotiating Committee.

\section{References}

CHAUDHARY, A. K. (2004) Examiners for the new OSCEs. Psychiatric Bulletin, 28,67.

DEPARTMENT OF HEALTH (2003) Terms and Conditions of Service 2003. An Agreement between the BMA's Central Consultants and Specialist Committee and The Department of Health for Consultants in England. London: Department of Health

NHS MODERNISATION AGENCY (2003) Preparation for Job Planning Record of Workload and

Commitments (http:// www.modern.nhs.uk/consultants/ 16263/diary.doc).

NHS MODERNISATION AGENCY (2004a) CCIT Update, issue 14, 30 January (http://www.wise.nhs.uk/ sites/workforce/retaining anddevelopingstaff/ Consultant $\% 20$ Contract $\% 20$ Document $\% 20$ Library/1/CCIT\%20 Update/CCIT\%20Update\%2014.pdf). NHS MODERNISATION AGENCY (2004b) Appeals in Consultant Job Planning and Pay Progression Disputes. Model Protocol (http:// www.modern.nhs.uk/consultants/ appeals.PDF).

WALKER, N. (2004) Not only examiners! Psychiatric Bulletin, 28, 228

M. E. Jan Wise Consultant Psychiatrist, 13-15 Brondesbury Road, London NW2 2AU; e-mail: jan.wise@nhs.net 